\title{
Economia brasileira na década de oitenta e seus reflexos nas condições de vida da população*
}

\author{
The Brazilian economy of the 80's and its impact on the living conditions of \\ the population
}

\author{
Ana Maria H. Ometto, Maria Cristina O. Furtuoso, Marina Vieira da Silva \\ Departamento de Economia Doméstica da Escola Superior de Agricultura Luiz de Queiroz (ESALOUSP) - Piracicaba, \\ $S P$ - Brasif
}

\begin{abstract}
A economia brasileira na década de 80 atravessou uma das mais graves crises de sua história, a qual resultou na estagnaçāo do Produto Interno Bruto e em taxas de inflaçāo sem precedentes. Apesar desse quadro económico crítico os indicadores sociais apresentaram evoluçăo positiva. Foi mostrado que, embora as famflias brasileiras adotassem como estratégla para o enfrentamento desta crise a super utillzação da força-de-trabalho familiar no mercado de trabaiho, a evoluçāo da renda $\theta$ de pobreza nesse periodo foi deśavorável. Concluiu-se que a ampliação dos dispêndios e transformaçăo das formas de implementaçāo das políticas públicas nas áreas de saúde e nutriçāo sāo fatores declsivos no desempenho dos indicadores sociais.
\end{abstract}

Qualidade de vida. Economia. Fatores socioeconômicos.

\section{Introduçăo}

A despeito dos percalços enfrentados pela economia brasileira durante a década de oitenta, manifestados na profunda crise que se instaura nos seus anos iniciais, nas marchas e contramarchas que refletem as dificuldades de retomada do crescimento e que resultam na virtual estagnação do Produto Interno Bruto (PIB) per capita nesse período, além do aumento das desigualdades de renda que acompanha a aceleração do procesşo inflacionário da segunda metade da década, a análise de uma série de indicadores sociais surpreende ao registrar a ocorrência de progressos significativos.

O presente trabalho objetiva contribuir para a discussão acerca dos motivos que levaram a essa aparente contradição.

\section{Padrão de Vida: Alguns Determinantes}

O padrão de vida de uma população depende de um conjunto de fatores dentre os quais destacam-se a renda familiar computada em termos reais, complementada ou não pela produçāo caseira de mercadorias e os benefícios sociais públicos e privados usufruídos por essa população.

A renda familiar, por sua vez, para grande parte das famílias é composta de salários decorrentes da venda da força de trabalho através de relação empregatícia, formalmente estabelecida, e de trabalhos que produzem renda, no que se convencionou denominar "setor informal" da economia, e onde se incluem urna série de atividades ocupacionais que, do ponto de vista da organização do trabalho, não se estruturam segundo os moldes capitalistas de produção. Dentre estes pode-se mencionar o trabalho por conta própria subordinado a uma única empresa, o pequeno vendedor de serviços, a pequena "empresa" familiar que se concentra no comércio e indústria de tamanho reduzido (confeitaria, confecções, e outras), e o emprego doméstico. 
Coletivizando parcial ou totalmente os rendimentos obtidos por essas diferentes formas, a família adquire então as mercadorias necessárias a sua sobrevivênvia, as quais, através do trabalho doméstico, são transformadas para adequá-las ao uso desejado.

Desta forma, o padrão de vida de uma população vai depender dos espaços que se abrirem no mercado formal e informal de trabalho, dos salários e demais rendimentos nominais obtidos versus as taxas de inflação (e os preços relativos) verificados, além dos benefícios oferecidos pelos setores público e privado.

Freqüentemente a expansāo observada no setor informal nāo reflete uma opção dos trabalhadores, mas sim a estratégia por eles utilizada para fazer face às circunstâncias adversas geradas pela crise do emprego formalmente estabelecido. Desta forma, aumenta a participação de trabalhadores neste setor durante as crises e, como o espaço econômico de que đispóem se restringe na mesma ocasiāo, os níveis de renda per capita aí gerados se tornam problematizados $s^{29}$

Por outro lado, uma das primeiras manifestações das crises é a queda do nível do emprego formalmente estabelecido, a qual usualmente se inicia no setor de bens de capital mas, pelo efeito multiplicador, difunde-se pelos demais. Numa economia industrial esta redução dos níveis de emprego pode ser acompanhada pela queda dos salários reais em decorrência de dois fatores básicos: o primeiro refere-se ao fato de que o aumento no desemprego ocasiona redução do poder de barganha dos sindicatos, o que pode, por ocasião das negociações coletivas, levá-los a aceitar reajustes menores do que as taxas de inflação registradas*; e o segundo, ao fato de que nessas economias os preços, longe de serem variáveis de ajuste, são determinados pelos custos, de forma que a redução da utilização da capacidade produtiva, ao implicar maiores custos fixos unitários gera pressões altistas nos preços e, dada a defasagem com que são reajustados os salários nominais, traz inevitáveis perdas salariais.

Portanto, espera-se que o impacto das crises na situação econômica das famílias seja negativo, tanto pela redução no volume de emprego e nos níveis de salário vigentes, quanto pela queda nos rendimentos per capita dos inseridos no setor informal.

Este impacto pode ser atenuado por mudanças na composição do emprego, no sentido do crescimento da participação no mercado de trabalho dos chamados trabalhadores "secundários" (cônjuges e filhos, principaimente).

Tais "arranjos" familiares estão associados ao ciclo de vida familiar e expressam, não só as dimensões simbólicas que definem os papéis socialmente atribuídos aos diversos membros da familia, mas também as possibilidades concretas de absorção desta mão-de-obra diferenciada no mercado de trabalho'.

Os movimentos compensatórios das dotaç̃es das verbas públicas para as políticas sociais se constituem também numa forma importante de atenuar os efeitos da crise sobre a populaçāo. Entretanto tais gastos, além de usualmente refletirem o calendário eleitoral ${ }^{24}$, ainda freqüentemente assumem um comportamento procíclico, quando na realidade deveriam ter caráter anticíclico ${ }^{20}$.

Findas essas consideraçōes teóricas, procederse-á a uma análise compacta da evolução da economia brasileira nos anos oitenta, centrando a atenção na questão do endividamento externo e seus reflexos nos desajustes internos da nossa economia nesse período.

\section{A Crise de Endivldamento Externo e o Desajuste Interno da Economia Brasileira nos Anos Oltenta}

No início dos anos oitenta há uma brusca reversão na trajetória de crescimento seguida pela economia brasileira e esta mergulha na mais grave crise de sua história.

O PIB per capita, que de 1970 a 1980 vinha se expandindo à taxa média de $6,1 \%$ a.a., diminui $13 \%$ entre 1980 e 1983. A tímida recuperação apresentada no período de 1984-89 leva o valor desse indicador apenas a retornar aos níveis observados no início da década ${ }^{\text {", }}$, de forma que se populariza a idéia de que os anos oitenta se constituíram para a economia brasileira, na "década perdida".

As raízes dessa crise, que se manifesta inicialmente como uma crise de endividamento externo, mas que rapidamente passa a se traduzir no desajuste interno da economia, estão nas políticas adotadas na década anterior, quando a opção pela manutenção do crescimento econômico após o primeiro choque do petróleo, e, mais do que isso, a busca do saito definitivo no aprofundamento do processo de substituição de importações, levaram o Estado brasileiro a assumir um padrão de financiamento baseado no crescente endividamento 
externo. Neste processo, a participação do setor privado na dívida externa se reduz de $67 \%$, no período $1972 / 73$ para $23 \%$ no final da década ${ }^{4}$.

O segundo choque do petróleo em 1979 e o brusco aumento das taxas de juros intemacionais verificado, viriam a aprofundar a crise extema brasileira através de uma série de mecanismos: pelo salto nos juros da dívida; por reorientar os fluxos de capital preferencialmente para os EUA e Europa; e pelo impacto negativo sobre os preços relativos das "commodities", itens importantes da nossa pauta de exportação.

Após a moratória mexicana, com a paralisação da entrada de capital externo, a reciclagem da dívida passou a exigir a realização de saldos comerciais crescentes e um ajustamento brutal da política econômica dos países devedores.

Entretanto, tais superávits comerciais viriam a se traduzir em sérios desequilíbrios na economia brasileira, pois, na verdade o problema não se esgota na questão da transferência de recursos, mas se complica pelo fato de que os superávits são obtidos basicamente pelo setor privado, enquanto a responsabilidade da dívida é do setor público ${ }^{31}$. Ou seja, os saldos gerados em dólar pelo setor privado deveriam ser transformados pelo governo em cruzeiros, pela emissão monetária ou pela colocação de títulos junto ao público, com os previsíveis efeitos inflacionários e/ou recessivos.

Em consequiência, aprofunda-se o endividamento do setor público pela capitalização dos juros da dívida, e a poupança privada vai crescentemente se colocando a serviço da rolagem da dívida pública, comprometendo o crescimento econômico.

$\mathrm{O}$ que agrava a situação é que à medida que as expectativas que os agentes financeiros têm sobre a capacidade do governo saldar seus compromissos vão se tornando cada vez mais desfavoráveis, tais agentes passam a exigir que os títulos apresentem juros maiores e liquidez máxima, provocando a deterioração das condições de financiamento da dívida pública interna.

Assim, a transferência de recursos privados para o governo e deste para as economias centrais viria a se transformar num elemento profundamente desestabilizador, e o desajuste externo a se traduzir no desajuste interno da economia brasileira.

A elevaçẫo das taxas de juros, além de resultar no agravamento das contas públicas, provacaria ainda a aceleração das taxas de inflação através de dois mecanismos: pelo seu impacto direto sobre os custos (com o custo financeiro passando a representar parcela crescente do custo total das mercadorias) e pelo seu impacto indireto, via elevação dos custos fixos unitários ocasionada pelos seus efeitos recessivos.

Desta forma, a inflação apresenta a primeira mudança de patamar em 1983 (como consequiência do agravamento da crise e da própria política cambial no período), se reduz acentuadamente em 1986 , sob a influência do Plano Cruzado, e volta a crescer sensivelmente nos três últimos anos da década, apesar dos sucessivos choques heterodoxos.

A crise econômica além de gerar altas taxas de desocupação masculina ( $4,9 \%$ no auge da crise, em 1983 ) e feminina $(4,8 \%$, no mesmo ano), ainda levou a uma forte retração no mercado de trabalho formal, e, em contrapartida, ao crescimento da proporção dos trabalhadores sem vínculos formais. Nesse sentido, a participação dos empregados sem carteira assinada cresce de $41,9 \%$ em 1981 para $47,2 \%$ em 1983, e apenas em 1987 retorna a níveis próximos aos do início da década $(41,7 \%)^{10}$.

Resumindo, a crise do endividamento extemo manifestada na economia brasileira na década de oitenta reflete-se em desequilibrios internos que impactam desfavoravelmente na situação econômica da população principalmente através da queda dos níveis de emprego (e crescimento da proporção de trabalhadores sem vínculos formais) observada nos anos iniciais da década, e da aceleração da inflação verificada mais nitidamente nos seus anos finais.

\section{A Família na Força-de-Trabalho}

Durante os anos oitenta persiste na economia brasileira o processo de incorporação das cônjuges e filthos no mercado de trabalho.

$\mathrm{Na}$ verdade este processo já vinha se intensificando na década anterior, quando, numa conjuntura de crescimento econômico acelerado, a influência de um conjunto de fatores, dentre os quais a política salarial repressiva do período e a dissolução das relações de produção pré-capitalistas no campo, foi neutralizada pelas famílias de baixa renda através da super utilização de seus membros como trabalhadores assalariados.

Conforme enfatizam Pastore e col. ${ }^{20}$, durante a década de setenta, conjugada a uma considerável expansão nos níveis de emprego, a melhoria na renda familiar e a diminuição dos níveis de pobreza foi obtida graças ao que esses autores denominam trabalho (considerando como sobrecarga a existência de jomada de trabalho superior a 48 horas semanais e a utilização de crianças e/ou adultos não disponíveis) cresce de 34,8 para $48,8 \%$. 
A participação da mulher na Populaçāo Economicamente Ativa-PEA se eleva de $21 \%$ para $28 \%$ e as taxas diferenciadas de crescimento segundo o estado civil verificadas favorecem 0 aumento da participação da cônjuge na força de trabalho. Desta forma em 1980 as mulheres casadas passam a constituir $36 \%$ da PEA feminina, enquanto em 1970 eram apenas $27 \%$.

A crise dos anos oitenta não interrompe esse processo.

Jatobâ $^{14}$, buscando investigar a sensibilidade cíclica da participação dos "trabalhadores secundários" da família, determinou as taxas de participação da família na força de trabalho (TPFFT)* nas regióes metropolitanas do Nordeste e Sudeste brasileiros nos anos 1978, 1983 e 1986. Observou que nesse período ocorre intensificação da participação dos membros da família no mercado de trabalho, sendo que as TPFFT do Sudeste foram maiores do que as do Nordeste, e que a TPFFT das familias chefiadas por mulheres superaram a das chefiadas por homens.

A respeito deste último aspecto, outros trabalhos tambem têm apontado para a maior mobilização do grupo familiar das familias chefiadas por mulheres, sugerindo que, dado os diferenciais de rendimento entre os sexos vigentes na nossa sociedade, a chefia feminina gera a necessidade de que os velhos, crianças e adolescentes também colaborem para a composiçāo da renda familiar ${ }^{3.17}$.

Pela Tabela 1, percebe-se que a TPFFT varia inversamente com a renda do chefe, indicando que realmente as famílias buscam compensar os baixos rendimentos do chefe elevando a participação dos demais membros no mercado de trabalho.

No tocante à evolução da composição dos trabalhadores secundários, verificou-se que as mulheres cônjuges aumentaram forte e persistentemente sua participação no mercado de trabalho, enquanto que os filhos, parentes e agregados, apresentaram um crescimento bem menos significativo da sua participaçāo. Ou seja, a elevaçāo das TPFFT deveu-se basicamente à incorporaçāo das cônjuges, num movimento que aparenta ser governado mais por forças seculares do que por elementos conjunturais.

Os dados da Tabela 2 corroboram com essa idéia, mostrando que a atividade feminina no Brasil cresce ao longo de toda a década.

Os saltos relativamente maiores apresentados por essa taxa nos períodos de 1981 a 1983 e em 1990 poderiam dar suporte à argumentação de que seriam urna resposta às crises. Entretanto, tais taxas não refluem nos períodos de recuperação, o que sugere novamente que tais mudanças têm cunho mais permanente.

Poder-se-ia supor que esse crescimento da participação feminina na PEA tivesse resultado na diminuiçāo dos níveis de pobreza entre famílias. Entretanto, para tal seria necessário que se verificassem algumas condições adicionais: a primeira, que a elevaçāo da atividade feminina estivesse

Tabela 2. Taxa de atividade para pessoas de 10 anos ou mais de idade, 1981-90 - Brasil.

\begin{tabular}{rrrr}
\hline Ano & Homens & Mulneres & Total \\
\cline { 3 - 4 } 1981 & 74,6 & 32,9 & 53,4 \\
1983 & 74,8 & 35,6 & 54,8 \\
1984 & 74,6 & 35,6 & 54,8 \\
1985 & 76,0 & 36,9 & 56,1 \\
1986 & 75,7 & 36,8 & 55,8 \\
1987 & 76,6 & 38,6 & 57,1 \\
1988 & 75,9 & 38,7 & 56,8 \\
1989 & 75,8 & 38,7 & 56,7 \\
1990 & 75,3 & 39,2 & 56,7 \\
\hline
\end{tabular}

Fonte: Dados de 1981-1989- IBGE ${ }^{10}$. Sintese dos Indicadores de Pesqulsa Básica da PNAD de 198†-1989, Tabela 3.3; dados de 1990. Anuário Estatístico do Brasil de 1992

Tabela 1. Taxas de participação da familla na força de trabalho, segundo ciasse de renda

\begin{tabular}{|c|c|c|c|c|c|c|}
\hline \multirow[t]{2}{*}{ Renda } & \multicolumn{3}{|c|}{$\begin{array}{c}\text { Áreas Metropolitanas } \\
\text { do Nordeste }\end{array}$} & \multicolumn{3}{|c|}{$\begin{array}{c}\text { Areas Metropolitanas } \\
\text { do Sudeste }\end{array}$} \\
\hline & 1978 & 1983 & 1986 & 1978 & 1983 & 1986 \\
\hline $\begin{array}{l}0 \text { a } 1 \text { SM } \\
1 \text { a } 2 \text { SM } \\
2 \text { a } 5 \text { SM } \\
5 \text { a } 10 \mathrm{SM} \\
10 \theta+S M\end{array}$ & $\begin{array}{l}0,6305 \\
0,5504 \\
0,5232 \\
0,5130 \\
0,4743\end{array}$ & $\begin{array}{l}0,6150 \\
0,5554 \\
0,5384 \\
0,5528 \\
0,5392\end{array}$ & $\begin{array}{l}0,6447 \\
0,5887 \\
0,5730 \\
0,5529 \\
0,5914\end{array}$ & $\begin{array}{l}0,6725 \\
0,6068 \\
0,5763 \\
0,5450 \\
0,5329\end{array}$ & $\begin{array}{l}0,6735 \\
0,6241 \\
0,5922 \\
0,5844 \\
0,5892\end{array}$ & $\begin{array}{l}0,6980 \\
0,6549 \\
0,6241 \\
0,6261 \\
0,6088\end{array}$ \\
\hline
\end{tabular}

Fonte: Jatobá' ${ }^{14}$,

SM - Salário-Mínimo

\footnotetext{
* Definiu a TPFFT como a razāo entre os membros da familia com 10 anos ou mais ocupados e procurando trabalho e a totali-
} dade dos membros com 10 anos ou mais. 
concentrada nas famúlias de menor poder aquisitivo; e a segunda, que a maior participaçâo das cônjuges não estivesse associada à perda do emprego elou dos niveis salariais dos chefes.

No tocante à primeira condição, os dados da Tabela 1, embora com a restrição de se referirem apenas às regiōes metropolitanas do Nordeste e Sudeste, permitem perceber que as famílias. cujos chefes têm renda mais elevada, têm aumentado a sua TPFFT a um ritmo superior ao daquelas cujos chefes têm menor rendimento. Ou seja, o crescimento da atividade dos trabalhadores secundários foi, nesse período. menos expressivo justamente para as famílias de menor poder aquisitivo.

Por outro lado. não se pode verificar se a segunda condiçâo é obedecida pelo fato das publicações disponíveis (Censos Demográficos e PNAD's) não permitirem o acompanhamento longitudinal das famílias. Entretanto, Ramos ${ }^{3: 3}$ verificou que o impacto da crise dos anos oitenta foi mais acentuado sobre os trabalhadores masculinos de menor qualificação.

Desta forma. a despeito da intensificaçăo do trabalho familiar observada nesse período, os indi. cadores da renda e de sua distribuição, e o dos níveis de pobreza vigentes na nossa sociedade mostram uma evolução desfavorável.

\section{Pobreza e Desigualdade entre Famílias}

A Tabela 3 foi elaborada com base em dados obtidos por Hoffmann" para o rendimento familiar médio e mediano e índices de concentração de renda (Gini) e de pobreza (Proporçâo de Pobres) para o Brasil de 1979 a 1990.

Em termos da evolução dos rendimentos médio e mediano pode-se perceber o impacto negativo da crise nos anos iniciais da década (até 1984) e tam. bém muito claramente os efeitos positivos (mas de curta duração) do Plano Cruzado e do período préeleitoral de 1989. Como resultado dessas marchas e contramarchas ao término da década tais rendimentos ainda năo haviam conseguido recuperar os patamares observados em 1979.

Os dados mostram também uma trajetória da desigualdade de renda que é marcada pela estabilidade entre 1979 e 1985 , seguida por uma brusca redução em 1986 (novamente como efeito benéfico do Plano Cruzado) e um intenso crescimento no período 1987-89.

Desta forma. a desigualdade de rendimentos entre famílias. medida através do índice de Gini, eleva-se de 0.597 em 1980 para 0.603 em 1990. e a parcela da renda apropriada pelos $50 \%$ mais pobres da população cai de 12.2 para $11,7 \%$. Podese mencionar também que o crescimento da desigualdade observado nos anos finais da década está, segundo Hoffmann", associado à aceleração da inflação.

A inflação elevada impacta sobre as medidas de desigualdade de duas maneiras: provocando aumento real da desigualdade, decorrente do menor poder de se proteger da inflaçāo de certos grupos (os assalaridados. pensionistas e outros, cujos rendimentos são reajustados com atraso) e um aumento aparente. causado principalmente pelo crescimento

Tabela 3. Distribuição das familias de acordo com o rendimento familiar, no Brasil, de 1979 a 1990: rendimento familiar médio (M) iridice Ginil (G), percentagem da renda correspondente aos $50 \%$ mais pobres (50), aos $10 \%$ mais ricos $\left(10^{+}\right)$e aos $5 \%$ mais ricos $\left(5^{+}\right)$, percentagem de pobres $(\mathrm{H})$.

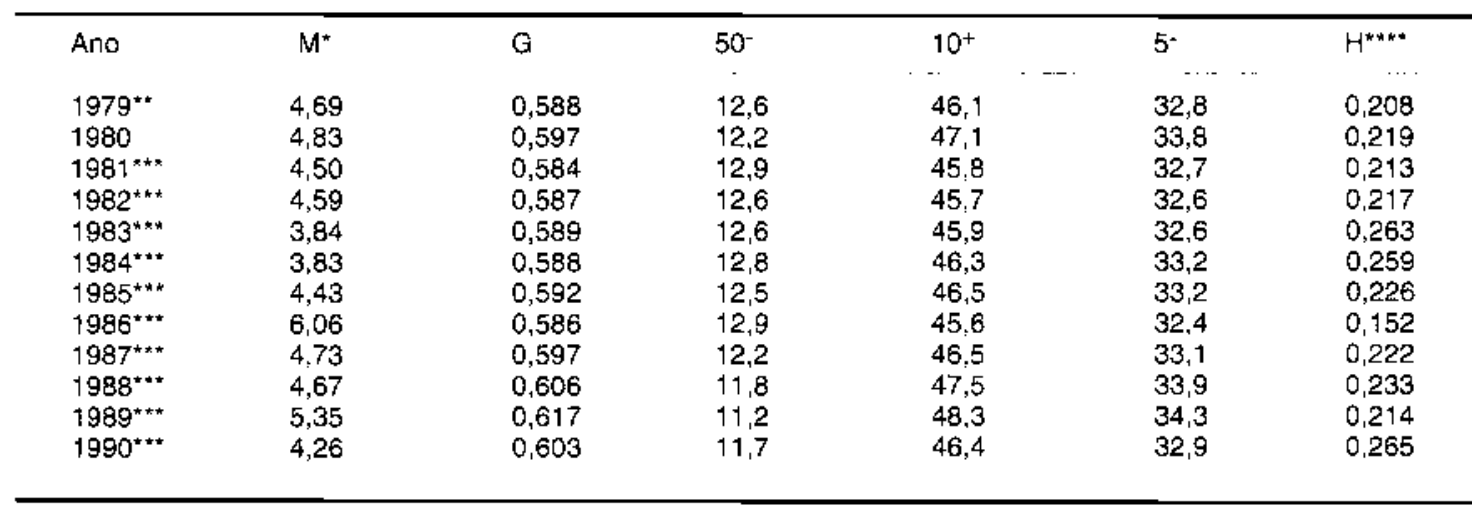

* Mês civil nos anos anteriores a 1986.

** Excluindo a área rural da Regiảo VII (Norte e Centro-Oeste, excluido o Distrito Federal).

** Excluindo a área rural da Regiäo Norte.

**** Limite de 1 salário-mínimo de agosto de 1980.

Extraida de Hoffmann"1. 
dos erros de declaração que ocorrem com maior freqüência nos períodos da inflação acelerada".

A conjugação desses movimentos das medidas de tendência central (rendimentos médio e mediano) e das de desigualdade resulta na elevação dos níveis de pobreza nos anos iniciais da década (1979/83-84), na clara reversão dessa tendência no biênio 1985/86 e, novamente, no seu crescimento de 1987 em diante*.

Ao término da década os indicadores dos níveis de pobreza absoluta mostram uma deterioração significativa da situação econômica das familias brasileiras, com o percentual de famílias com rendimento inferior a um salário mínimo se elevando de 20,8, em 1979, para 26,5, em 1990.

\section{A Evolução de Indicadores Sociais}

A crise enfrentada pela economia brasileira na primeira metade dos anos oitenta e o aumento dos níveis de desigualdade observado na segunda, embora resultassem em elevação dos níveis de pobreza absoluta, não impedem que a evolução de uma série de indicadores sociais seja positiva.

$\mathrm{Na}$ verdade, a análise do comportamento das taxas de mortalidade infantil e da esperança de vida ao nascer do brasileiro ao longo dos últimos sessenta anos, nos permite concluir que a "década perdida" no aspecto social foi a de sessenta e não a de oitenta, como poder-se-ia supor pela observaçăo da renda e da pobreza.

As Tabelas 4 e 5 mostram, respectivamente, as taxas de mortalidade infantil e da esperança de vida ao nascer no Brasil e grandes Regiöes no período 1930/1980.

A justaposição desses dados, com os da Tabela 6 , referentes à mortalidade infantil no Brasil e em São Paulo, nos anos oitenta, comprova que a evolução favorável desses indicadores só se interrompe nos anos sessenta.

Na década de sessenta a economia brasileita apresentou crescimento econômico moderado, com o PIB per capita aumentando cerca de $36 \%$. Entretanto, tal crescimento não se traduziu em redução dos níveis de pobreza devido ao intenso processo de concentração de renda verificado no período, de forma que a percentagem de pessoas com rendimento inferior ao salário mínimo (defiacionado pelo valor de agosto de 1980) se reduz apenas de 58 para 55. De qualquer modo, a evolução dos indicadores econômicos é positiva, visto que além do mencionado crescimento đo PIB

Tabela 4. Esperança de vida ao nascer, segundo as grandes reglóes, 1930-1980.

\begin{tabular}{lccccc} 
Grandes Pegiōes & $1930 / 40$ & $1940 / 50$ & $1950 / 60$ & $1960 / 70$ & $1970 / 80^{*}$ \\
\hline Brasil & 42,74 & 45,90 & 52,37 & 52,67 & 60,08 \\
Norte & 40,44 & 44,26 & 52,62 & 54,06 & 64,17 \\
Nordeste & 38,17 & 38,69 & 43,51 & 44,38 & 51,57 \\
Sudeste & 44,00 & 48,81 & 56,96 & 56,89 & 63,59 \\
Sul & 50,09 & 53,33 & 60,34 & 60,26 & 66,98 \\
Centro-Oeste & 48,28 & 51,03 & 56,40 & 55,96 & 64,70
\end{tabular}

* Estimativas sujeitas à revisão, em virtude de năo estar concluido o processo de avaliação de consistência das intormaçōes sobre nascidos vivos e mascidos mortos do Censo Demográfico de 1980. Fonte: IBGE .

Tabela 5. Taxa de mortalidade infantil, segundo as grandes regiōes, 1930-1980.

\begin{tabular}{lrrrrr} 
Grandes Regiöes & $1930 / 40$ & $1940 / 50$ & $1950 / 60$ & $1960 / 70$ & $1970 / 80^{*}$ \\
\hline Brasll & 158,27 & 144,73 & 118,13 & 116,94 & 87,88 \\
Norte & 168,42 & 151,70 & 117,14 & 111,39 & 72,31 \\
Nordeste & 178,71 & 176,34 & 154,94 & 151,18 & 121,36 \\
Sudeste & 152,82 & 132,62 & 99,97 & 100,24 & 74,50 \\
Sul & 127,37 & 114,31 & 86,88 & 87,19 & 61,80 \\
Centro-Oeste & 134,81 & 123,56 & 102,17 & 103,90 & 70,32
\end{tabular}

- Estimativas sujeitas à revisão, em virude de náo estar concluído o processo de avaliação de consistência das informaçōes sobre filthos nascidos vivos e nascidos mortos do Censo Demográfico de 1980. Fonte: IBGE:

\footnotetext{
* Hoffmann" utilizou como critério para o estabelecimento da linha de pobreza a renda familiar equivalente a um salário-mínimo de agosto de 1980 . Outros autores têm construldo o limite de renda definidor da pobreza através do rendimento minimo necessário

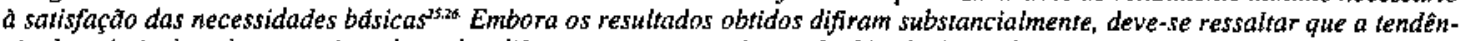
cia dos niveis de pobreza registrados pelos diferentes autores ao longo da década é semelhante.
} 
Tabela 6. Taxa de mortalidade infantil. Brasil e Estado de Sāo Paulo, 1980-1989.

\begin{tabular}{rrr}
\hline Ano & Brasil & São Pautlo \\
1980 & 75,0 & 51,2 \\
1981 & 68,4 & 49,3 \\
1982 & 64,5 & 47,9 \\
1983 & 66,7 & 42,3 \\
1984 & 65,9 & 44,9 \\
1985 & 58,1 & 36,4 \\
1986 & 53,2 & 36,2 \\
1987 & 51,0 & 33,7 \\
1988 & 47,5 & 33,9 \\
1989 & 45.0 & 30,9 \\
\hline
\end{tabular}

Fonte: $\mathrm{BBGE}^{3}, \mathrm{SEADE}^{5}$.

per capita, aumentam também a renda média entre pessoas economicamente ativas (em cerca de $23 \%$ ) e a mediana (em $6 \%)^{i}$.

Já na década de oitenta. apesar do crescimento significativo da participação das cônjuges no mercado de trabalho. há pelas razóes discutidas anteriormente. redução da renda familiar média e aumento dos níveis de pobreza.

Entretanto. essa década se apresenta favorável no aspecto social mesmo quando comparada à de setenta, o que é surpreendente tendo em vista as taxas de crescimento econômico então vivenciadas pela economia brasileira (quando o PIB per capita cresceu $81 \%$, o rendimento médio entre pessoas economicamente ativas $76 \%$ e a porcentagem de pobres se reduziu a $34 \%)^{11}$.

$\mathrm{Na}$ medida em que as taxas de mortalidade infantil e proporcional caem a niveis mais baixos. deixam de ser indicadores sensíveis da qualidade de saúde da populaçâo. Em tais circunstâncias. segundo Bengoa', passam a ganhar importância os estudos antropométricos, que repetidos periodicamente constituem métodos epidemiológicos que permitem avaliar o estado de saúde e desenvolvimento.

A comparação dos dados sobre estatura média de meninas e meninos de 6 e 7 anos, da Pesquisa Nacional de Saúde e Nutrição (PNSN)'2. realizada de julho a setembro de 1989 (ou seja. com crianças que nasceram no auge da crise). com os obtidos pelo Estudo Nacional de Despesas Familiares (ENDEF) de 1974/75 (referindo-se, portanto. às que vivenciaram todo o "milagre econômico") permite constatar crescimento significativo da estatura das crianças brasileiras das áreas rural e urbana (Tabela 7 ).

$\mathrm{Na}$ Tabela 8 pode-se verificar decréscimo de cerca de $60 \%$ na prevalência de déficits ponderais severos entre as crianças menores de cinco anos estudadas nas pesquisas de 1975 e 1989 . o que reforça a idéia de melhoria do estado nutricional da população infantil.

Seria interessante complementar estas informações com a análise da evolução da morbidade infantil nesse período. Entretanto, sabe-se que, no Brasil, os dados referentes ao perfil de morbidade da população em geral e. em particular das crianças, são precários.

De acordo com Monteiro: ${ }^{\circ}$ apenas um grupo restrito de doenças infecto-contagiosas é de notificação compulsória no País. Mesmo assim. na maioria das vezes é bastante falha a cobertura do registro. Os raros dados de morbidade disponíveis provêm geralmente de estudos de demanda de laboratórios e serviços de assistência à saúde. Segundo o citado autor há, no entanto, o inconveniente de que estes dados, frequientemente, não permitem inferências populacionais seguras.

As razões para esse bom desempenho dos indicadores de saúde, num período onde os indicadores econômicos foram tâo negativos, devem ser buscadas. então, nos movimentos compensatórios das dotações das verbas públicas para as políticas sociais e nas próprias transformações observadas no conjunto desses gastos.

Nesse sentido, a literatura ressalta a importância do crescimento das taxas de alfabetização e educação, da expansâo da rede de saneamento básico. da melhoria da assistência prestada pela rede básica de saúde e da major cobertura dos programas de suplementação alimentar *

No tocante à evolução das taxas de alfabetização e da educação básica da população brasileira. a Tabela 9. elaborada por Monteiro e col. ${ }^{17}$, possibilita observar a evolução positiva desses indicadores, que é inclusive, mais acentuada para mulheres em idade reprodutiva, o que pode repercutir na saúde infantil através da melhoria dos cuidados maternos.

A Tabela 10 permite notar o crescimento significativo do percentual de domicílios com abastecimento de água através de rede geral. com coleta de lixo e iluminação elétrica. crescimento este muito maior do que o que seria mera decorrência do processo de urbanização observado.

Considerando-se o conjunto dos gastos sociais realizados pelo Governo Federal no período 1980 89. pode-se notar o corte de recursos ao longo do biênio 1983-84 e a elevação contínua destes gastos na segunda metade da década, dentro da abordagem do "tudo pelo social" que foi a tônica da Nova República. Desta forma. fica caracterizado o comportamento pró-cíclico de tais despesas, e não anticíclico. como seria o recomendado (Tabela 11 ). 
Tabela 7. Altura média (cm) de crianças de ambos os sexos de 6 e 7 anos, Brasil - 1975 e 1989

\begin{tabular}{|c|c|c|c|c|c|c|}
\hline \multirow{3}{*}{ Altura } & \multicolumn{6}{|c|}{ Populaçâo } \\
\hline & \multicolumn{2}{|c|}{ Urbana } & \multicolumn{2}{|c|}{ Rural } & \multicolumn{2}{|c|}{ Total } \\
\hline & $F$ & M & $\mathrm{F}$ & M & $F$ & $M$ \\
\hline \multicolumn{7}{|l|}{$\begin{array}{c}6 \text { Anos } \\
\text { Pesquisa (1975) }\end{array}$} \\
\hline Altura Média $(A)$ & 112,3 & 113,0 & 110,3 & 110.1 & 111,4 & 111,7 \\
\hline Desvio-Padrăo & 7,2 & 7,4 & 6.7 & 7,0 & 7,0 & 7,4 \\
\hline \multicolumn{7}{|l|}{ Pesquisa(1989) } \\
\hline Altura Média (B) & 115,4 & 116,1 & 113,2 & 112,5 & 114,7 & 115,7 \\
\hline Desvio-Padrāo & 6,7 & 6,4 & 6.0 & 6.1 & 6,5 & 6,5 \\
\hline Incremento Médio $(B-A)^{*}$ & 3,1 & 3,1 & 2,9 & 2,4 & 3,3 & 4,0 \\
\hline \multicolumn{7}{|l|}{7 Anos } \\
\hline Altura Média (A) & 118,4 & 118,4 & 115,3 & 115,3 & 116,8 & 117,0 \\
\hline Desvio-Padrão & 7,7 & 7,9 & 6,8 & 7,1 & 7,4 & 7,4 \\
\hline \multicolumn{7}{|l|}{ Pesquisa (1989) } \\
\hline Altura Media (B) & 120,8 & 121,2 & 118,9 & 118,2 & 120,3 & 120,4 \\
\hline Desvio-Padrāo & 6,3 & 6,9 & 7,0 & 7,3 & 7,2 & 7,1 \\
\hline incremento Médio $(B-A)^{*}$ & 2,8 & 2,8 & 3,8 & 2,9 & 3,5 & 3,4 \\
\hline
\end{tabular}

Fonte: Iunes e Monteiro's

* Todos os incrementos significativos A p<0,001.

Tabela 8. Prevalência (\%) de déficits ponderais severas* em crianças menores de 5 anos - Brasil: 1975 e 1989.

\begin{tabular}{|c|c|c|c|c|c|}
\hline \multirow[t]{2}{*}{ Extrato } & \multicolumn{2}{|c|}{ Amostra } & \multicolumn{2}{|c|}{ Percentual } & \multirow{2}{*}{$\begin{array}{l}\text { Variação } \\
\text { Percentual** }\end{array}$} \\
\hline & 1975 & 1989 & 1975 & 1989 & \\
\hline Brasıl Urbano & 24.784 & 3.895 & 14,6 & 5,6 & 61,6 \\
\hline Brasil Rural & 11.623 & 3.571 & 22,9 & 10,6 & 53,7 \\
\hline Total & 36.407 & 7.466 & 18,4 & 7,1 & 61,4 \\
\hline
\end{tabular}

A análise da transformação na composição desses dispêndios aponta para o favorecimento das

Tabela 9. Alfabetização e educaçào básica*. Brasil: 1970,1980 e 1988.

\begin{tabular}{|c|c|c|c|}
\hline Alfabet|zação/Educação & 1970 & 1980 & 1988 \\
\hline \multicolumn{4}{|l|}{ Taxa de alfabetizacāo (\%) } \\
\hline Populaçăo: 10 anos ou mais & 65.9 & 74,7 & 81,5 \\
\hline Mulheres de 25 a 29 anos & 67,7 & 81,4 & $90,3-$ \\
\hline \multicolumn{4}{|l|}{ Eơcação Básica* $(\%)$} \\
\hline Populacāo: 10 anos ou mais & 31.7 & 479 & 57.1 \\
\hline Mulheres de 25 a 29 anos & 35.5 & 602 & 72,3 \\
\hline
\end{tabular}

Fonte: Monteiro e col'3.

* 4 ou mais anos de educaçâo. áreas de alimentação e nutrição e de educação e cultura.

Lma análise superficial dos dados poderia sugerir que a elevação dos percentuais empregados em tais setores teria sido financiada pela redução dos dispêndios em habitação e urbanismo (Fig.1). Entretanto, esta conclusão é imprópria, visto que a lógica de captação de recursos para tais setores é diferente, com as verbas para a área de habitação e urbanismo sendo provenientes do Sistema Financeiro da Habitação, e captadas através das cadernetas de poupança. enquanto as da área de alimentação e nutrição são oriundas em grande parte do orçamento público.

Observando-se os gastos federais nos diferentes programas da área de alimentação $\mathrm{e}$ nutrição no período 1980-1993 (Tabela 12) chama atençâo a mudança de patamar de tais gastos em 1985 (quando o crescimento é de mais de $70 \%$ ). Além disso, na segunda metade da década, as verbas para esta área crescem acentuadamente.

Ao longo dos dois anos do Governo Collor. há uma drástica reversão desta tendência e os recursos a ela destinados, em 1992, se reduzem ao irrisório percentual de $16 \%$ do montante dispendido em 1990. Em 1993 observa-se uma retomada de tais gastos. $O$ único programa que se mantém em todo o período analisado foi o Programa 
Tabela 10. Distribuiçảo percentual dos domicílios particulares*, segundo algumas características - 1981 - 1989 . Brasil.

\begin{tabular}{|c|c|c|c|c|c|c|c|c|}
\hline Características dos domicilios & 1981 & 1983 & 1984 & $\uparrow 985$ & 1986 & 1987 & 1988 & 1989 \\
\hline Total $^{* *}$ & 100,0 & 100,0 & 100,0 & 100,0 & 100,0 & 100,0 & 100,0 & 100,0 \\
\hline $\begin{array}{l}\text { Situaçảo do domicílio } \\
\text { Urbana } \\
\text { Rural }\end{array}$ & $\begin{array}{l}73,7 \\
26,3\end{array}$ & $\begin{array}{l}74,6 \\
25,4\end{array}$ & $\begin{array}{l}75,2 \\
24,8\end{array}$ & $\begin{array}{l}75,5 \\
24,5\end{array}$ & $\begin{array}{l}75,6 \\
24,4\end{array}$ & $\begin{array}{l}75,8 \\
14,2\end{array}$ & $\begin{array}{l}76,3 \\
23,7\end{array}$ & $\begin{array}{l}76,7 \\
23,3\end{array}$ \\
\hline $\begin{array}{l}\text { Abastecimento de água } \\
\text { Rede Geral } \\
\text { Outra }\end{array}$ & $\begin{array}{l}60,1 \\
39,9\end{array}$ & $\begin{array}{l}64,6 \\
35,4\end{array}$ & $\begin{array}{l}66,2 \\
33,8\end{array}$ & $\begin{array}{l}67,9 \\
32,1\end{array}$ & $\begin{array}{l}69,9 \\
30,1\end{array}$ & $\begin{array}{l}70.0 \\
30,0\end{array}$ & $\begin{array}{l}70,9 \\
29,1\end{array}$ & $\begin{array}{l}72,2 \\
27,3\end{array}$ \\
\hline $\begin{array}{l}\text { Destino do lixo } \\
\text { Coletado } \\
\text { Outro }\end{array}$ & $\begin{array}{l}49,2 \\
50,8\end{array}$ & $\begin{array}{l}54,1 \\
45,9\end{array}$ & $\begin{array}{l}56,1 \\
43,9\end{array}$ & $\begin{array}{l}57,7 \\
42,3\end{array}$ & $\begin{array}{l}58,5 \\
41,5\end{array}$ & $\begin{array}{l}59,8 \\
40,2\end{array}$ & $\begin{array}{l}60,1 \\
39,9\end{array}$ & $\begin{array}{l}62,9 \\
37,1\end{array}$ \\
\hline Huminação Elétrica & 74,9 & 77,9 & 79,4 & 81,1 & 83,2 & 84,4 & $85: 9$ & 86,9 \\
\hline Filtro & 51.7 & 53,1 & 53,6 & 54,5 & 55,9 & 55.5 & 57,0 & 56,8 \\
\hline
\end{tabular}

\footnotetext{
* Exclusive os domicílios da área rural da Regiāo Norte.

** Inclusive os domicilios sem declaraçẫo de qualquer caracteristica.

Fonte: $\mid B G E^{* c}$.
}

Tabela 11. Gastos sociais - Brasil: 1980-1989.

\begin{tabular}{|c|c|c|c|c|c|}
\hline \multirow[t]{3}{*}{ Ano } & \multirow{2}{*}{$\begin{array}{l}\text { Área Social } \\
\text { Gastos US\$ } \\
\text { Milhōes 1989* }\end{array}$} & \multirow{3}{*}{$\begin{array}{l}\text { Gastos USS** } \\
\text { Milhōes } 1989\end{array}$} & \multicolumn{2}{|c|}{ Saúde e Nutriçāo } & \multirow{3}{*}{$\begin{array}{l}\% \text { Gasto } \\
\text { Social }{ }^{* *}\end{array}$} \\
\hline & & & $\begin{array}{l}\text { Indice } \\
1980=100\end{array}$ & $\% \mathrm{PIB}^{\star \star}$ & \\
\hline & $\ldots+-\ldots \ldots$ & & & & \\
\hline 1980 & $33,387.30$ & 210.34 & 100,00 & 0,06 & 0.63 \\
\hline 1981 & $34,342.19$ & 219.79 & 104,49 & 0,06 & 0.64 \\
\hline 1982 & $35,875.32$ & 276.24 & 131,33 & 0,08 & 0,77 \\
\hline 1983 & 30.691 .00 & 306.91 & 145,91 & 0.09 & 1.00 \\
\hline 1984 & $26,588.50$ & 332.35 & 158,01 & 0,09 & 1,25 \\
\hline 1985 & $31,102.55$ & 609.61 & 289,82 & 0,16 & 1,96 \\
\hline 1986 & $35,140.47$ & 903.11 & 429.36 & 0,22 & 2,57 \\
\hline 1987 & $37,511.63$ & 967.80 & 460.11 & 0,23 & 2,58 \\
\hline 1988 & $38,996.93$ & 889.13 & 422,71 & 0.21 & 1,28 \\
\hline 1989 & $41,529.38$ & 805.67 & 383,03 & 0,18 & 1,94 \\
\hline
\end{tabular}

Fonte: " Cálculo dos autores, com base em informaçōes contidas em lunes e Monteiro ${ }^{13}$.

* Iunes e Monteiro's, citando Piola e col. ${ }^{22}$

Nacional de Alimentaçào Escolar-PNAE* que. no Governo Collor passa a absorver cerca de $70 \%$ dos investimentos na área. Por outro lado, o Programa Nacional do Leite para Crianças CarentesPNLCC, criado no governo Samey, chegou a consumir $52.2 \%$ dos recursos em 1990 e foi extinto em 1991.

É importante mencionar ainda que as alterações em termos das políticas sociais não se restringem às referentes ao montante e composição dos gastos, mas envolvem também aquelas ligadas às formas de sua implementaçâo.

No Brasil, as discussōes sobre a descentralização/municipalização ganham espaço em meados da década de oitenta com o processo de redemocratização do País, mas já no ano de 1983, os Estados de São Paulo e Rio de Janeiro, antecipan- do-se à iniciativa federal, deram início a algumas experiências de municipalização do Programa de Merenda Escolar, que até o final da década foram estendidas à quase totalidade dos Programas desses Estados ${ }^{28}$. No âmbito nacional, a partir do Governo Itamar, a municipalização do PNAE se estende aos demais Estados:".

É também simultânea e assegurada pela Constituiçâo de 1988 a descentralização que se instala na área de Saúde. quando os direitos dos beneficiários se desvinculam da Previdência e passam a ser considerados universais.

O impacto das alterações na composição dos gastos sociais e o das transformaçōes na sua forma de implementaçăo sobre a evolução dos indicadores sociais é um tema ainda pouco explorado e que merece uma análise mais profunda. 

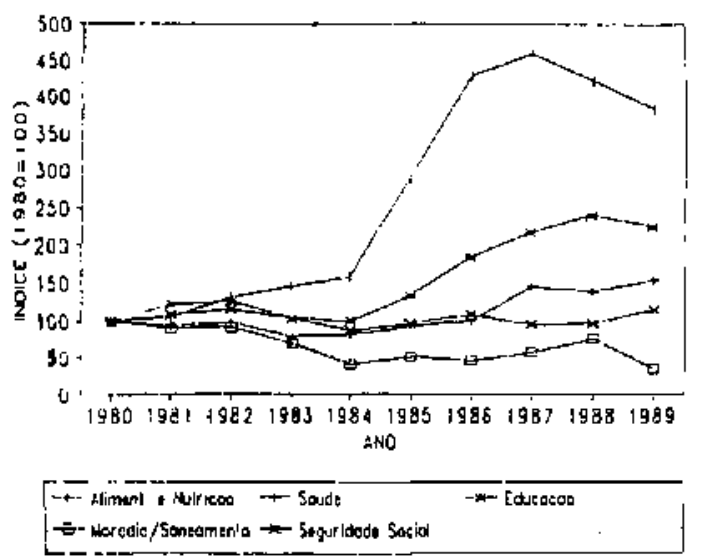

Fonte: Iunes e Monteiro'

Figura. Gasto Federal, área social. Brasil, 1980-1989.

Por outro lado, considerando que os programas de suplementação alimentar tem, de uma maneira geral, favorecido as regiões urbanas, os Estados mais desenvolvidos e os pobres nāo indigentes ${ }^{15}$ (portanto menos necessitados), permanece como sugestão para futuras pesquisas uma análise regional que contraponha a evoluçāo dos indicadores econômicos e sociais com a das políticas da área de saúde e nutriçāo.
Finalmente, deve-se evitar otimismo descabido, atentando-se para o fato de que os ganhos obtidos, em relação aos mencionados indicadores, nāo estabelecem para o país posição confortável na área social, nem mesmo quando os demais países da América Latina são tomados como referência. Apesar do Brasił ser considerado a principal economia industrial da região, e dos bons resultados obtidos no tocante à cobertura das vacinaçōes e assistência médica nos partos, ainda assim é o que apresenta maior desigualdade de distribuição de renda, uma das maiores proporçōes da populaçāo abaixo da linha da pobreza e consideráveis taxas de mortalidade infantil e analfabetismo, maiores inclusive do que as de países sem nenhuma expressão econômica'.

\section{Conclusões}

O trabalho buscou mostrar que a evolução favorável de uma série de indicadores sociais no Brasil dos anos oitenta mostrou-se correlacionada com a ampliação dos dispêndios e transformação nas formas de implementação das políticas públicas nas áreas de saúde e nutrição.

Tabela 12. Investimento totel per capita* (US dólares) e por programa em percentagem do total, para aiguns programas entre 1980 e $1993^{* *}$

\begin{tabular}{|c|c|c|c|c|c|c|c|c|c|c|}
\hline Ano & $\begin{array}{c}\text { Totaii** } \\
\text { Per Capita } \\
\text { US } \times 1.000\end{array}$ & PNS/PSA & $\begin{array}{l}\text { PNAE } \\
\text { PAIE }\end{array}$ & $\begin{array}{l}\text { PCA } \\
\text { PAN }\end{array}$ & PAOCAB & $\begin{array}{l}\text { PROAB } \\
\text { PAP }\end{array}$ & PNLCC & $\begin{array}{l}\text { Leite } \\
\text { Saúde }\end{array}$ & $\begin{array}{l}\text { Gente } \\
\text { I e It }\end{array}$ & $\begin{array}{l}\text { PRODEA } \\
\text { Feijão }\end{array}$ \\
\hline 1980 & 1,53 & 39,7 & 35,9 & 12,3 & 7,1 & - & - & - & - & \\
\hline 1981 & 1,86 & 30,1 & 44,4 & 11,6 & 3,6 & 2,2 & - & - & - & - \\
\hline 1982 & 2,36 & 32,3 & 51,5 & 8,4 & 2,1 & 2,2 & - & - & - & - \\
\hline 1983 & 2,00 & 38,5 & 42,9 & 5,7 & 0,9 & 7,4 & - & - & - & - \\
\hline 1984 & 2,32 & 38,5 & 50,1 & 4,0 & 0,4 & 6,0 & - & - & - & - \\
\hline 1985 & 3,92 & $40,1^{* * *}$ & 54,2 & 2,0 & 0,1 & 3,6 & - & - & - & - \\
\hline 1986 & 5,73 & 26,8 & $56,4^{\ldots \ldots}$ & $5,1^{* * \cdots * *}$ & 0,3 & 6,0 & 4,8 & - & - & - \\
\hline 1987 & 6,46 & 18,7 & 38,8 & 8,8 & 0,4 & 1,9 & 31,0 & - & - & - \\
\hline 1988 & 6,56 & 11,5 & 34,5 & 13,5 & 0,1 & 0,3 & 39,9 & - & - & - \\
\hline 1989 & 7,27 & 8,0 & 31,8 & 14,4 & 0,1 & 0,1 & 45,5 & - & - & - \\
\hline 1990 & 8,90 & 9,0 & 31,4 & 6,9 & - & - & 52,2 & - & - & - \\
\hline 1991 & 2,75 & 11,8 & 69,4 & 1,5 & - & - & 1,6 & - & $14,9^{* * \cdots \cdots * *}$ & - \\
\hline 1992 & 1,39 & 7,9 & 74,6 & - & - & - & 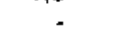 & - & $16,9^{\star \star \star * x * \star}$ & - \\
\hline 1993 & 3,54 & - & 84,4 & - & - & - & - & 6,0 & - & $9.4^{* *}$ \\
\hline
\end{tabular}

* Foram calculados os investimentos totais per capita conforme sisternática adotada por Medici'.

O tamanho da populaçāo, ano a ano, foi obtido com base nos valores de populaçąo residente dos censos de 1980 e 1991, fazendo-se interpolaçס̄es admltindo uma taxa geometrica de crescimento constante ao longo dos 11 anos.

* O PAT não é incluido face a dificuldade de calcular o investimento do estado; PNIAM e carèncias específicas não estro inclúdos.

*** De 1978 a 1989, segundo relatório 8831 BR, Banco Mundial; de 1990 em diante, Peliano e Beghin ${ }^{2}$.

**** OPNS passou a PSA, modiflcando a idade das crianças alvo para $\mathrm{O}$ a 4 anos.

***** Em 1986 foi acrescentado a PAIE.

***** A partir de 1986 formulados foram substituldos por alimentos naturais e foi introduzido um componente de saúde.

****** O cálculo não inclui o custo de reposição do estoque.

Fonte: Peliano e Begin ${ }^{21}$ apud Silva ${ }^{27}$. 
Através da análise dos dados apresentados foi possível verificar a expressiva melhora das condiçōes de vida da população brasileira, numa década onde a nossa economia atravessou a mais grave crise de sua historia, as taxas de inflação atingiram níveis sem precedentes e, onde, apesar da intensificação do uso da força de trabalho familiar, ocorreu aumento das desigualdades de renda e da pobreza.

Desta forma, ficou destacado o papel decisivo desempenhado pelo investimentos na área social sobre o padrāo de vida do brasileiro, atenuando os efeitos da crise e viabilizando o aumento de "direitos" de parcela expressiva da populaçāo.

Também foi mencionada a necessidade de que a distribuição dos đispêndios na área de alimen- tação e nutrição seja reorientada de forma a atingir mais intensamente os grupos de risco e os bolsōes de pobreza.

Ressalta-se ainda a importância de avaliações contínuas dos programas sociais, visando a otimização dos recursos, os quais, por sua vez, espera-se que sejam ampliados a medida em que se reduza a sonegação e aumente a arrecadação.

Embora a evoluçāo positiva dos indicadores esteja aparentemente associada às mudanças percorridas pelas políticas sociais do período, tais políticas devem ser encaradas como açōes complementares, passíveis de implementaçāo no curto prazo, na busca de amenizar os graves problemas enfrentados pela populaçāo brasileira, e não como substitutas das transformaçōes mais profundas que devem ser perseguidas pela nossa sociedade.

\section{Referências Bibliográficas}

1. BANCO MUNDIAL. Poverty and income distribution in Latin America: the story of the 1980s. Washington, D.C., 1993. (Report $\mathrm{n}^{\mathrm{2}}$ 27).

2. BENGOA, J.M. El problema de la malnutrición. Crón. OMS, 28:3-7, 1974.

3. BRUSCHINI, G.C. Estrutura familiar de trabalho na Grande Săo Paulo. Cad. Pesq., 72:39-57, 1990.

4. CRUZ, P.D. Notas sobre o endividamento externo brasileiro nos anos Sessenta. In: Belluzzo, L.G.M. \& Coutinho, R. Desenvolvimento capitalista no Brasil. Sào Paulo ed. Brasiliense, 1983. v. 2, p. $57-106$

5. FUNDAÇÃO SEADE. Movimento do registro civil 1970-1989. São Paulo, 1990.

6. FUNDAÇÃO IBGE. Censo demográfico 19701980. Rio de Janeiro, 1980.

7. FUNDAÇÃO IBGE. Estudo nacional de despesas familiares: 1974 - 1975. Rio de Janeiro, 1977.

8. FLNDAÇÃO IBGE. Estatisticas bistónicas do Brasil: séries econômicas, demogräficas $e$ soctais de 1950 a 1988. 2a. ed. Rio de Janeiro, 1977.

9. FUNDAÇĀO IBGE. Estatisticas do registro ctvil, 1977 - 1989. Rio de Janeiro, 1990.

10. FUNDAÇÃO IBGE. Sintese de indicadores de pesquisa básica da PNAD de 1981-1989. Rio de Janeiro, 1990.

11. HOFFMAN.v, R. Desigualdade e pobreza no Brasil no período 1979-90. In: Encontro Brasileiro de Econometria, 14², Campos do Jordào, 1992. Anats. São Paulo, 1992. v. 1.

12. INSTITUTO NACIONAL DE ALIMENTAÇÃO E NUTRIÇẢO. Pesquisa nacional de saũde $e$ nutriçäo: resultados preliminares. Brasília, 1990.
13. IUNES, R.F. \& MONTEIRO, C.A. Razôes para a melhoria do estado nutricional das crianças brasileiras nas décadas de 70 e 80 . São Paulo, NUPENS/USP/UNICEF, 1993.

14. JATOBÁ, J. A família na força de trabalho: Brasil metropolitano - 1978/1979. In: Encontro Nacional de Estudos Populacionais, $7^{\circ}$, Águas de São Pedro, 1990. Anais. São Paulo, ABEP, 1990. v. 2 p. $147-76$

15. LOPES, J.R.B. Política social: subsidios estatísticos sobre a pobreza e acesso a programas sociais no Brasil. In: Seminário de "Desenvolvimento Social e Pobreza, Centro Brasileiro de Planejamento e Análise, São Paulo, 1994. p. 125.

16. MEDICI, A.C. O gasto com saúde nos anos 80 . In: Simões org. Perfil estatistico de crianças e mâes no Brasil:mortalidade infantil $e$ satide na década de 80 . Rio de Janeiro, IBGE, 1989.

17. MONTALI, L. Arranjos familiares: o esforço coletivo para viver na Grande Sào Paulo. Cad Pesq., 72:58-69. 1990.

18. MONTEIRO, C.A. Saude e nutrição das crianças de Săo Paulo. Sâo Paulo, HLCITEC/EDUSP, 1988.

19. MONTEIRO, C.A. et al. Nutritional status of Brazilian children: trends from 1975 to 1989. Bull. World Healtb Organ., 70:65766, 1992.

20. PASTORE, J. et al. Mudança social e pobreza no Brasil 1970-1980.(O que ocorreu com a familia brasileira?). Sào Paulo, FIPE/Pioneira, 1983.

21. PELIANO, A.M.M.T. \& BEGHIN, N. O papel do Estado na área de alimentação e nutrição. Brasília, IPEA, 1992.

22. PIOLA, S.F. et al. A conta social consolidada:1980-1990. Brasília, IPEA, s.d. 
23. RAMOS. L,RA, The distribution of earnings in Brasil: 1976-1985. Berkcley, 1990. [Ph.D. Dissertation of Lniversity of California].

24. REZENDE, F. A política social e a crise econômica. In: Chahad, J.P. \& Cenini. R. org. Crise e infância no Brasil. Sào Paulo. LXICEF IPE: LSP. 1988.

25. ROCHA. S. Pobreza no Brasil: parâmetros básicos e resultados empíricos. Pesq. Planej. Econ., 22. 5+1-60. 1992

26. ROMÁO. M.C. Distribuição de renda, pobreza e desigualdades regionais no Brasil: In: Camargo. J.M. \& Giambiagi, F. org. Distribuçào de renda no Brasil, São Paulo. Editora Paz e Terra, 1991.

27. SILVA, A.C. De l'angas a Itamar; politica e programas de alimentaçào entriçào. Sào Paulo IEA L'SP, 1994.
28. SILYA. M.V. Contribuiçào do programa de merenda escolar-ciclo básico para as recomendaçòes nutricionais de escolares da cidade de Piracicaba. Sào Paulo. 1991. [Dissertaçào de Mestrado - Faculdade de Saúde Pública dá ['SP].

29. SOLZA. P.R.C. A determinação de salúrios e do emprego nas economias atrasadas. Campinas. 1980. [Tese de Doutorado - Instituto de Filosofia e Ciencias Humanas da LXICANIP].

30. VIANNA. S.M. et al. Os servicos de saúde durante a recessào. In: Chahad, J.P. \& Cervini, R. org. Crise e Infância no Brasil. Sào Paulo, LNICEF. IPE LSP. 1988. p. 139183.

31. WERNEC. R.L.F. Poupança estatal. divida externa e crise financeira do setor público. Pesq. Planej. Econ., 16: 551-־4. 1986.

\section{Abstract}

In the 80's the Brazilian economy underwent one of the most severe crises of its history, resulting in the stagnation of the gross national product and inflation rates such as never previously reportted. Despite this unfavorable scenario social indicators have presented a positive evolution. This work shows that although the Brazilian family has adopted the over-use of the family work force as a strategy for facing this crisis on the work market, the evolution of both income and poverty in that period were poor. The increase of expenses and the transtormation of the forms of implementation of public policy in the health and nutrition areas are shown to be decisive factors in the performance of social indicators.

Quality of life. Economy. Socioeconomic factors. 